\title{
Low Income as a Vulnerable Factor to the Effect of Noise on Insomnia
}

\author{
Choongman Park', Chang Sun Sim², Joo Hyun Sung ${ }^{3}$, Jiho Lee², \\ Joon Ho Ahn ${ }^{4}$, Young Min Choe ${ }^{5}$, and Jangho Park ${ }^{4} \bowtie$ \\ ${ }^{1}$ Department of Psychiatry, Asan Medical Center, University of Ulsan College of Medicine, Seoul, Republic of Korea \\ ${ }^{2}$ Department of Occupational \& Environmental Medicine, Ulsan University Hospital, University of Ulsan College of Medicine, Ulsan, \\ Republic of Korea \\ ${ }^{3}$ Department of Occupational \& Environmental Medicine, Gyeongsang National University Changwon Hospital, Gyeongsang National University \\ School of Medicine, Changwon, Republic of Korea \\ ${ }^{4}$ Department of Psychiatry, Ulsan University Hospital, University of Ulsan College of Medicine, Ulsan, Republic of Korea \\ ${ }^{5}$ Department of Neuropsychiatry, Hallym University Dongtan Sacred Heart Hospital, Hwaseong, Republic of Korea
}

Objective The present study aimed to examine the potential mediating effect of income level on the association between noise exposure and insomnia.

Methods 706 individuals were evaluated in conjunction with 2014 noise map data from Seoul, South Korea. Cross-sectional analysis was performed to examine differences in noise level according to household income, while three separate logistic regression models were used to examine factors influencing insomnia. Odds ratios (ORs) were calculated after adjusting for depression, anxiety, auditory acuity and noise sensitivity in the first model. Analyses were adjusted for sociodemographic variables in the second model, lifestyle factors and medical illnesses in the third model.

Results Noise level was significantly associated with an increased risk of insomnia in the low-income group, although no such association was observed in the high-income group. Groups exposed to $>60 \mathrm{~dB}$ of noise (Lden; day-evening-night equivalent) exhibited a 1.79fold increase in the incidence of insomnia relative to those exposed to $<50 \mathrm{~dB}$. The result was significant after adjusting sociodemographic variables, although not significant when adjusted for lifestyle factors and medical illnesses.

Conclusion Individuals with low income may be more vulnerable to the deleterious effects of noise exposure on health. Various aspects including income should be considered to ascertain the influence of noise on insomnia. Psychiatry Investig 2018;15(6):602-612

Key Words Noise, Insomnia, Income, Mental health, Cross-sectional study.

\section{INTRODUCTION}

Insomnia affects as many as one in three adults in the United Kingdom, escalating to chronic insomnia in approximately $20 \%$ of cases. ${ }^{1}$ Previous studies reported that $22.8 \%$ of adults in Korea are affected by insomnia, ${ }^{2}$ the prevalence of which is known to increase with age. Furthermore, the risk of insomnia is higher among women, those with medical or psy-

Received: April 20, 2017 Revised: September 29, 2017

Accepted: January 14, 2018

$\triangle$ Correspondence: Jangho Park, MD, PhD

Department of Psychiatry, Ulsan University Hospital, University of Ulsan College of Medicine, 877 Bangeojinsunhwando-ro, Dong-gu, Ulsan 44033, Republic of Korea

Tel: +82-52-250-4985, Fax: +82-52-250-7078, E-mail: drpark98@naver.com

(c) This is an Open Access article distributed under the terms of the Creative Commons Attribution Non-Commercial License (http://creativecommons.org/licenses/by$\mathrm{nc} / 4.0$ ) which permits unrestricted non-commercial use, distribution, and reproduction in any medium, provided the original work is properly cited. chological disorders, and those who work in shifts. ${ }^{3}$ Recent studies have consistently demonstrated that environmental or transportation-related noise in residential areas may also influence various aspects of sleep. ${ }^{4-7}$

The World Health Organization defines environmental noise as unwanted sound originating from all sources (e.g., transportation, industrial, recreational and etc.), with the exception of workplace noise. ${ }^{4}$ The main causes of environmental noise are associated with roadways, railroads, airports, and construction sites. According to a report by the European Union, $40 \%$ and $20 \%$ of the population are exposed to noise $\geq 55$ decibels ( $\mathrm{dB}$ ) or $\geq 65 \mathrm{~dB}$ during the day, respectively, while $30 \%$ are exposed to noise exceeding $55 \mathrm{~dB}$ at night. Moreover, when all sources of transportation noise are considered that over $50 \%$ of the population is exposed to noise exceeding the auditory comfort level. ${ }^{8} \mathrm{~A}$ recent report dem- 
onstrated that $16.6 \%$ of individuals in Seoul are exposed to road traffic noise at $65 \mathrm{~dB}$ or higher during the day, while $34.8 \%$ are exposed to noise at $55 \mathrm{~dB}$ or higher at night. ${ }^{9}$ Moreover, a total of 2,416 cases of harm caused by noise were reported in Korea during 2010, $62 \%$ of which were related to psychological harm. ${ }^{10}$

Over the last 30 years, interest in the deleterious effects of environmental noise on mental and physical health has grown. In 2009, the World Health Organization established standards for identifying and reducing sources of environmental noise associated with sleep disorders, ${ }^{11}$ resulting in the publication of the Burden of Disease from Environmental Noise. ${ }^{4}$ Since the publication of this report, accumulating evidence has suggested that environmental noise is significantly associated with the development of cardiovascular diseases, ${ }^{12}$ tinnitus, ${ }^{13}$ decreased cognitive function, ${ }^{14}$ and sleep disorders. ${ }^{15}$ Thus, environmental noise represents a major public health issue that places the physical and psychological health of individuals in noise-heavy areas at risk. ${ }^{5}$

Evidence has increased in the last decade that noise events elicit awakenings at relatively low exposure levels in laboratory and field study environments. ${ }^{16}$ Polysomnography (PSG) is the golden standard for measuring sleep in laboratory setting which record electrical brain activity, muscle tone, and eye movements. ${ }^{17}$ Especially in intensive care unit, sleep abnormalities occur frequently. There are consistent PSG findings among different studies which include multiple short bouts of sleep during the day and night, a relatively normal total sleep time, significant sleep fragmentation, and severe reductions in stage 3 and REM sleep. ${ }^{18-20}$ In field studies, sleep is usually assessed with questionnaires due to large sample size and cost. Increased exposure of nocturnal road traffic noise is closely related to subjective evaluated sleep which include delayed sleep onset latency, increased awakening, overall decreased in sleep quality. ${ }^{6}$ Environmental noise results in frequent awakening and disruptions during sleep, thereby increasing fatigue and decreasing work performance during the day and potentially leading to chronic insomnia. ${ }^{4,21}$ One study shows that there is no significant difference in sleep quality when the same subjects were exposed to noise in laboratory or field setting. ${ }^{22}$

Although there are various methods for evaluating the influence of noise exposure on health, noise annoyance is among the most commonly utilized in recent studies. ${ }^{23,24}$ Nowadays several European studies have revealed a correlation between the objective noise index derived from noise maps and cardiovascular diseases, insomnia, and annoyance. ${ }^{25,26}$ Although standards and policies for appropriate noise exposure have been implemented in Europe based on these findings, ${ }^{11}$ such studies have yet to be conducted in Korea.
The noise exposure varies according to the residential area. And socioeconomic status greatly influences an individual's selection of his or her residential area. Poor residential environments have been associated with increased stress and lower levels of health-related quality of life, both of which may negatively impact health. ${ }^{27}$ While previous standards for addressing environmental inequalities were closely related to distance from locations that process pollutants such as trash, ${ }^{28}$ researchers have begun to increase their focus on the discomfort caused by environmental pollution and noise. ${ }^{29}$ Individuals with high income are afforded a greater number of options regarding noise, proximity to school or work, and convenience when choosing a residential environment. ${ }^{30,31}$ However, evidence regarding the relationship between income and noise remains inconsistent. Some studies have reported that higher-income areas are associated with higher levels of noise, ${ }^{32,33}$ while others have reported an inverse relationship between income and noise. ${ }^{34,35}$ Another study reported no correlation between income and noise. ${ }^{29}$ Such discrepancies may have resulted from the methods used to evaluate noise levels or the characteristics of the city in which these levels were measured, rendering it difficult to generalize the findings of these studies. ${ }^{32}$ However, it is known that low socioeconomic conditions can act as stressors or affect health behavior and lead to detrimental consequences. ${ }^{35}$ Especially in Seoul, housing prices have risen sharply due to lack of space and rapid urbanization. Therefore, the choice of residential environment varies depending on income level. In other words, the socioeconomic level is an important indicator for evaluating environmental safety factors such as the residential environment, and the low socioeconomic group may be much more vulnerable to environmental risk exposure and mental health problem. ${ }^{31}$ Thus, the influence of economic status must be considered when evaluating the effects of environmental factors on health.

The objective of this study was to identify the association between noise exposure and insomnia. We hypothesize that the effect of noise on insomnia is different by income level while considering varied demographic and sociodemographic backgrounds together. Finally, we examined the association again after considering additional health-related and lifestyle factors.

\section{METHODS}

\section{Participants}

The present study utilized 2014 noise map of Yangcheongu, Seoul. Residential regions were divided into three levels of noise exposure (less than 50, 50-59, and $\geq 60 \mathrm{~dB}$ ), following which a sample proportional to the population in each re- 
gion was calculated. A sampling design was used to accurately estimate the health effects of environmental noise. In this study, considering the influence of the noise level depending on the region, 'noise' was considered as the important parameter. In addition, by using the area sampling method using the information technology proposed by Woo and Kim, ${ }^{36}$ the latest update on the household list was conducted and samples were extracted. Between July 2015 and January 2016, a total of 1,000 participants from this region were surveyed after providing written informed consent. Respondents provided information regarding insomnia, depression, and other mental health-related symptoms, as well as that regarding demographics, health-related behaviors, shiftwork and medical conditions. Demographic information included age, gender, education level, marital status, residence period. Health-related behaviors included smoking, alcohol consumption, regular exercise, and caffeine intake. Shift work status was divided into shift and non-shift workers. We didn't subdivide the two shifts and the three shifts due to the small number of people. Respondents were also asked to provide information regarding diagnoses of medical diseases such as hypertension, hyperlipidemia and diabetes. Average monthly income was divided into less than 3 million KRW (Korean won) and 3 million KRW or more (approximately \$2700 USD). 131 subjects were missed in survey fill and out of remaining 869 patients, 45 subjects who are currently taking psychiatric medication, 31 subjects who have hearing loss due to ear disease, ear surgery or any medication, 49 subjects who have tinnitus, 35 subjects whose response accuracy less than 50 percent were excluded in the statistical analysis. A total of 709 respondents were finally included in this study. This study was approved by the Institutional Review Board of the Ulsan University Hospital (IRB No. 2014-08-008).

\section{Noise-related index}

Environmental noise was calculated in accordance with the 2002 European Commission Guidelines. ${ }^{37}$ Daytime noise $\left(\mathrm{L}_{\text {day }}\right)$, evening noise $\left(\mathrm{L}_{\text {evening }}\right)$, and nighttime noise $\left(\mathrm{L}_{\text {night }}\right)$ were measured in $\mathrm{dB}(\mathrm{A})$ based on the average noise level measured at 07:00-19:00, 19:00-23:00, and 23:00-07:00, respectively. $\mathrm{L}_{\mathrm{den}}$ represents the noise index measured over 24 hours (day-evening-night), calculated using weighted values of 5 $\mathrm{dB}$ during the evening and $10 \mathrm{~dB}$ at night. ${ }^{37}$

In the present study, we utilized 2014 noise maps to calculate noise exposure for Yangcheon-gu, Seoul. The traffic noise level at the perimeter of each residential area was measured, and the noise maps were prepared using noise prediction software (Cadna A, DataKustik, Germany). As the European Environmental Agency defines $\mathrm{L}_{\mathrm{den}} 50 \mathrm{~dB}$ as the level at which clinical health effects are observed, ${ }^{38}$ we divided $L_{\text {den }}$ into the following three levels to examine the influence of each on insomnia: less than 50, 50-59, and $\geq 60 \mathrm{~dB}$. Auditory acuity and noise sensitivity were assessed via the single-item questionnaires on an 11-point Likert scale, where higher number indicates higher auditory acuity and noise sensitivity. Noise sensitivity scale had been translated according to the International Organization for Standardization Technical Specification $15,666 .{ }^{39}$

\section{Mental health-related index}

The degree of insomnia was determined based on the Insomnia Severity Index (ISI), while anxiety and depressionthat may also influence insomnia-were assessed using the StateTrait Anxiety Inventory (STAI) and Center for Epidemiologic Studies Depression scale (CES-D), respectively.

The ISI is a subjective index of insomnia developed by Morin, ${ }^{40}$ and the present study utilized a version adapted by Cho in 2004. ${ }^{41}$ The Insomnia Severity Index includes seven self-report questions scored from 0 to 4 points, for a total score ranging from 0 to $28 .^{42}$ The ISI is designed to detect the presence of sleep disturbances over the past 2 weeks, such as difficulty falling asleep, difficultly staying asleep and problems waking up too early. Items related to the severity of insomnia, satisfaction with sleep conditions, interference with functionality during the day and degree of impairment associated with sleep disturbances are also included. In the present study, an ISI score $\geq 10$ points was considered indicative of insomnia, based on the value identified as the optimal cut-off point in community research settings. ${ }^{43}$

The validity of the CES-D of depression has been demonstrated in previous studies. ${ }^{44,45}$ The CES-D contains 20 self-report questions, with a maximum score of 60 points. The degree of depression is measured based on the duration of six key depressive symptoms: ${ }^{44}$ depressed mood, feeling of guilt and worthlessness, feeling of helplessness and hopelessness, loss of appetite, psychomotor retardation and sleep disturbances. Higher scores are indicative of more severe depressive symptoms, with scores of 16 and 25 points typically used as indicators of probable and definite depression, respectively. In the present study, participants were considered to have depression when CES-D scores were $\geq 16$ points, based on screening standards utilized in previous studies. ${ }^{46}$

The STAI was developed by Spielberger et al. ${ }^{47}$ for the differentiation of clinically anxious groups in mental health settings. The present study utilized the Korean version of the STAI adapted by Kim and Shin. ${ }^{48}$ Among the 40 total questions related to state/trait anxiety, the present study utilized 20 questions associated with state anxiety. Each question is scored along a 4-point Likert scale, with higher scores indicative of higher levels of anxiety. In accordance with the results of the 
study conducted by Kim, ${ }^{49}$ a state anxiety score of 52 was used as the cut-off point, which was determined based on an average state anxiety score for university students.

\section{Statistical analysis}

The demographic data and key variables of all participants were divided according to income level. T-tests were used to compare consecutive variables, while chi-square analyses were used to compare categorical variables and to assess prevalence of depression, anxiety, and insomnia according to the degree of noise exposure.

Multilevel regression models were used to determine the influence of various factors on insomnia. In the first model, odds ratios (ORs) were used to determine the influence of noise exposure on insomnia. In the second model, the analysis was adjusted for demographic variables, while the ORs of lifestyle factors including shift work and medical illnesses were calculated in the third model. Regression analysis was then used to determine the tolerance and variance inflation factor (VIF) following correction for factors that may have influenced the results all three models (auditory acuity, noise sensitivity, anxiety, and depression). The results of this analysis revealed that the maximum VIF value between independent variables was 2.49 , and the minimum tolerance value was 1.07 , which indicated that there were no multicollinearity issues.

All analyses were performed using SPSS 21.0 (IBM SPSS

Table 1. Demographic characteristics of the study sample according to monthly income

\begin{tabular}{|c|c|c|c|c|c|}
\hline & \multirow[b]{2}{*}{ Total $(\mathrm{N}=709)$} & \multicolumn{2}{|c|}{ Monthly income } & \multirow[b]{2}{*}{ t or $\chi^{2}$} & \multirow[b]{2}{*}{$\mathrm{p}$ value } \\
\hline & & $\begin{array}{c}<3 \text { million KRW } \\
(2700 \text { USD) }(\mathrm{N}=358)\end{array}$ & $\begin{array}{c}\geq 3 \text { million KRW } \\
(2700 \text { USD) }(\mathrm{N}=351)\end{array}$ & & \\
\hline Age $($ mean \pm SD $)$ & $43.97 \pm 15.21$ & $44.97 \pm 17.66$ & $42.93 \pm 12.17$ & 1.770 & 0.077 \\
\hline Sex $(\%)$ & & & & 3.534 & 0.060 \\
\hline Male & $316(44.6)$ & $172(48.0)$ & $144(41.0)$ & & \\
\hline Female & $393(55.4)$ & $186(52.0)$ & $207(59.0)$ & & \\
\hline Residence period (years) & $7.51 \pm 7.24$ & $8.00 \pm 7.80$ & $7.00 \pm 6.58$ & 1.846 & 0.065 \\
\hline Education level (\%) & & & & 12.643 & $<0.001$ \\
\hline High school or less & $237(33.4)$ & $142(39.7)$ & $95(27.1)$ & & \\
\hline College or more & $472(66.6)$ & $216(60.3)$ & $256(72.9)$ & & \\
\hline Marital status (\%) & & & & 113.719 & $<0.001$ \\
\hline Single & $265(37.4)$ & $179(50.0)$ & $86(24.5)$ & & \\
\hline Married & $360(50.8)$ & $112(31.3)$ & $248(70.7)$ & & \\
\hline Etc.* & $84(11.8)$ & $67(18.7)$ & $17(4.8)$ & & \\
\hline Shift work status (\%) & & & & 2.217 & 0.091 \\
\hline Shift worker & $44(6.2)$ & $27(7.5)$ & $17(4.8)$ & & \\
\hline Non-shift worker & $665(93.8)$ & $331(92.5)$ & $334(95.2)$ & & \\
\hline Smoking (\%) & & & & 0.536 & 0.464 \\
\hline Yes & $106(15.0)$ & $57(15.9)$ & $49(14.0)$ & & \\
\hline No & $603(85.0)$ & $301(84.1)$ & $302(86.0)$ & & \\
\hline Alcohol (\%) & & & & 22.859 & $<0.001$ \\
\hline Yes & $304(42.9)$ & $122(34.1)$ & $182(51.9)$ & & \\
\hline No & $405(57.1)$ & $236(65.9)$ & $169(48.1)$ & & \\
\hline Exercise (\%) & & & & 7.891 & 0.005 \\
\hline Yes & $501(70.7)$ & $270(75.4)$ & $231(65.8)$ & & \\
\hline No & $208(29.3)$ & $88(24.6)$ & $120(34.2)$ & & \\
\hline Coffee (\%) & & & & 16.906 & $<0.001$ \\
\hline$<3$ cups/day & $551(77.7)$ & $301(84.1)$ & $250(71.2)$ & & \\
\hline$\geq 3$ cups/day & $158(22.3)$ & $57(15.9)$ & $101(28.8)$ & & \\
\hline Noise exposure $(\mathrm{dB})$ & $50.30 \pm 11.43$ & $48.97 \pm 10.86$ & $51.66 \pm 11.84$ & -3.153 & 0.002 \\
\hline
\end{tabular}

p-value was calculated using t-tests for continuous variables and chi-square tests for categorical variables. *other: divorce, separation, bereavement 
Statistics; IBM Corp., Armonk, NY, USA) for Windows, and the level of statistical significance was set at $\mathrm{p}<0.05$.

\section{RESULTS}

\section{Demographic characteristics}

The mean age of the final 709 research participants was $50.30 \pm 11.43$ years, and $44.6 \%$ were male. The mean length of residence was $7.51 \pm 7.24$ years, while the mean level of noise exposure $\left(\mathrm{L}_{\text {den }}\right)$ was $50.30 \pm 11.43 \mathrm{~dB}$. A total of 358 participants (50.5\%) reported an income of less than KRW 3 million. Level of noise exposure was significantly higher in the high-income group than in the low-income group (high-income: $51.66 \pm 11.84 \mathrm{~dB}$; low-income: $48.97 \pm 10.86 \mathrm{~dB}$; $\mathrm{p}=0.002)$. No significant differences in age, gender, education level, shift work status and residence period were observed between the two groups (Table 1).

\section{Prevalence of mental health disorders according to noise exposure}

The prevalence of insomnia among participants of the present study was $26.7 \%(n=189)$. Anxiety was observed in $5.1 \%$ $(n=36)$ of participants, while depression was observed in $4.8 \%$ $(n=34)$ of participants. Anxiety and depression were noted in $3.8 \%(n=13)$ and $4.4 \%(n=15)$ of participants in areas with $\mathrm{L}_{\mathrm{den}}<50 \mathrm{~dB}(\mathrm{n}=341), 4.8 \%(\mathrm{n}=9)$ and $4.8 \%(\mathrm{n}=9)$ of participants in areas with $\mathrm{L}_{\mathrm{den}}=50-59 \mathrm{~dB}(\mathrm{n}=189)$, and $7.8 \%(\mathrm{n}=14)$ and $5.6 \%(n=10)$ of participants in areas with $L_{d e n} \geq 60 \mathrm{~dB}(n=$ 179), respectively. There were no significant differences in noise exposure between patients with anxiety and depression based on income level (anxiety group $\chi^{2}=3.651, \mathrm{p}=0.056$; depression group $\chi^{2}=0.331, \mathrm{p}=0.565$ ) (Table 2).

\section{Influence of noise exposure on insomnia according to income level}

Our analysis revealed no significant increase in the prevalence of insomnia according to the degree of noise exposure (24.9\%, 27.0\%, 29.6\% at $\mathrm{L}_{\mathrm{den}}<50 \mathrm{~dB}, \mathrm{~L}_{\mathrm{den}}=50-59 \mathrm{~dB}, \mathrm{~L}_{\mathrm{den}} \geq 60$ $\mathrm{dB}$, respectively; $\chi^{2}=1.323, \mathrm{p}=0.250$ ). When participants were divided based on income levels, we observed a tendency for insomnia as the levels of noise exposure increased in the lowincome group $\left(25.4 \%, 28.6 \%, 37.8 \%\right.$ at $\mathrm{L}_{\mathrm{den}}<50 \mathrm{~dB}, \mathrm{~L}_{\mathrm{den}}=50-$ $59 \mathrm{~dB}, \mathrm{~L}_{\mathrm{den}} \geq 60 \mathrm{~dB}$, respectively; $\left.\chi^{2}=3.749, \mathrm{p}=0.053\right)$. No significant correlation was observed between noise level and

Table 2. Mental health according to level of noise exposure

\begin{tabular}{|c|c|c|c|c|c|c|}
\hline & Total $(\mathrm{N}=709)$ & $\mathrm{L}_{\mathrm{den}}<50(\mathrm{~N}=341)$ & $50 \leq \mathrm{L}_{\mathrm{den}}<60(\mathrm{~N}=189)$ & $60 \leq \mathrm{L}_{\mathrm{den}}(\mathrm{N}=179)$ & $\chi^{2}$ & $\mathrm{p}$ value \\
\hline Insomnia (\%) & & & & & 1.323 & 0.250 \\
\hline ISI $<10$ & $520(73.3)$ & $256(75.1)$ & $138(73.0)$ & $126(70.4)$ & & \\
\hline $\mathrm{ISI} \geq 10$ & $189(26.7)$ & $85(24.9)$ & $51(27.0)$ & $53(29.6)$ & & \\
\hline Anxiety (\%) & & & & & 3.651 & 0.056 \\
\hline STAI-X $<52$ & $673(94.9)$ & $328(96.1)$ & $180(95.2)$ & $165(92.2)$ & & \\
\hline STAI-X $\geq 52$ & $36(5.1)$ & $13(3.8)$ & $9(4.8)$ & $14(7.8)$ & & \\
\hline Depression (\%) & & & & & 0.331 & 0.565 \\
\hline CES-D $<16$ & $672(94.8)$ & $324(95.0)$ & $179(94.7)$ & $169(94.4)$ & & \\
\hline CES-D $\geq 16$ & $34(4.8)$ & $15(4.4)$ & $9(4.8)$ & $10(5.6)$ & & \\
\hline Missing & $3(0.4)$ & $2(0.6)$ & $1(0.5)$ & & & \\
\hline
\end{tabular}

p-value was calculated by chi-square tests. CES-D: Center for Epidemiologic Studies Depression Scale, ISI: Insomnia Severity Index, $\mathrm{L}_{\mathrm{den}}$ : dayevening-night sound level, STAI-X: State-Trait Anxiety Inventory-State Anxiety

Table 3. Prevalence of insomnia, depression, and anxiety according to level of noise exposure stratified by income level

\begin{tabular}{|c|c|c|c|c|c|c|}
\hline Income $<3$ million KRW & Total $(\mathrm{N}=358)$ & $\mathrm{L}_{\mathrm{den}}<50(\mathrm{~N}=193)$ & $50 \leq \mathrm{L}_{\mathrm{den}}<60(\mathrm{~N}=91)$ & $60 \leq \mathrm{L}_{\mathrm{den}}(\mathrm{N}=74)$ & $\chi^{2}$ & $\mathrm{p}$ value \\
\hline $\mathrm{ISI} \geq 10(\%)$ & $103(28.8)$ & $49(25.4)$ & $26(28.6)$ & $28(37.8)$ & 3.749 & 0.053 \\
\hline CES-D $\geq 16(\%)$ & $18(5.0)$ & $8(4.1)$ & $5(5.6)$ & $5(6.8)$ & 0.825 & 0.364 \\
\hline \multirow[t]{2}{*}{ STAI-X $\geq 52(\%)$} & $17(4.7)$ & $5(2.6)$ & $8(8.8)$ & $4(5.4)$ & 2.097 & 0.148 \\
\hline & $(\mathrm{N}=351)$ & $(\mathrm{N}=148)$ & $(\mathrm{N}=98)$ & $(\mathrm{N}=105)$ & & \\
\hline $\mathrm{ISI} \geq 10(\%)$ & $86(24.5)$ & $36(24.3)$ & $25(25.5)$ & $25(23.8)$ & 0.005 & 0.945 \\
\hline CES-D $\geq 16(\%)$ & $16(4.6)$ & $7(4.8)$ & $4(4.1)$ & $5(4.8)$ & 0.001 & 0.971 \\
\hline STAI-X $\geq 52(\%)$ & $19(5.4)$ & $8(5.4)$ & $1(1.0)$ & $10(9.5)$ & 1.472 & 0.225 \\
\hline
\end{tabular}

p-value was calculated by chi-square tests. CES-D: Center for Epidemiologic Studies Depression Scale, ISI: Insomnia Severity Index, $\mathrm{L}_{\mathrm{den}}$ : dayevening-night sound level, STAI-X: State-Trait Anxiety Inventory-State Anxiety, KRW: Korean won 


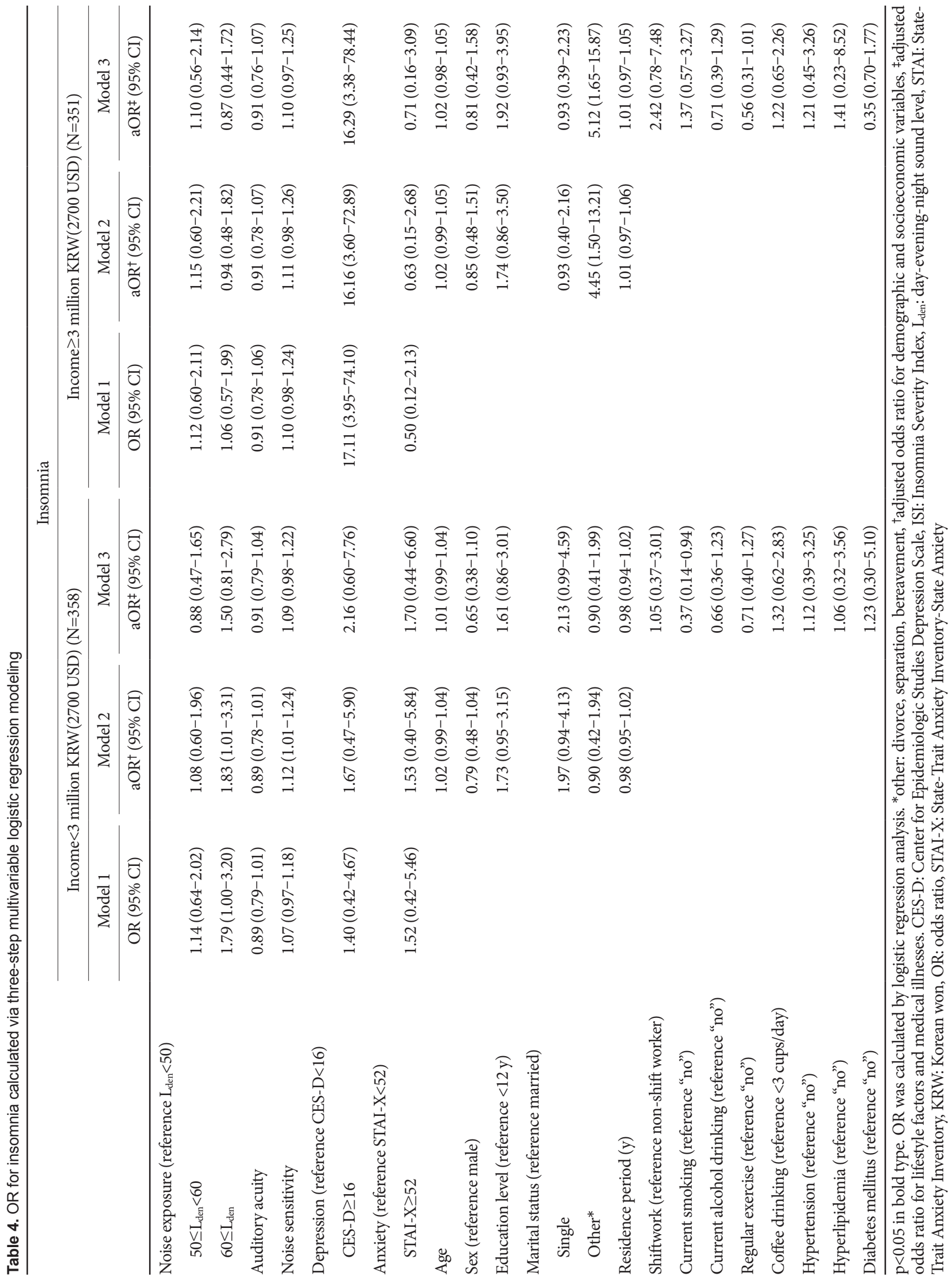


insomnia in the high-income group $(24.3 \%, 25.5 \%, 23.8 \%$ at $\mathrm{L}_{\mathrm{den}}<50 \mathrm{~dB}, \mathrm{~L}_{\mathrm{den}}=50-59 \mathrm{~dB}, \mathrm{~L}_{\mathrm{den}} \geq 60 \mathrm{~dB}$, respectively; $\chi^{2}=0.005$, $\mathrm{p}=0.945)$. Furthermore, no significant correlation was observed between noise level and depression/anxiety when participants were divided according to income level (Table 3).

\section{Multilevel logistic regression analysis of insomnia risk factors}

Multilevel logistic regression analysis was performed to compare the influence of each variable on insomnia. Our analysis revealed that increased noise exposure was associated with an increased risk of insomnia in the low-income group, although no significant difference was observed between noise exposure at $\mathrm{L}_{\mathrm{den}}<50 \mathrm{~dB}$ and $\mathrm{L}_{\mathrm{den}}=50-59 \mathrm{~dB}$. When analyses were adjusted for auditory acuity, noise sensitivity, anxiety, and depression (Model 1), the risk of insomnia increased 1.79fold for $L_{d e n} \geq 60 \mathrm{~dB}$, relative to that observed for noise levels of less than $50 \mathrm{~dB}$ (OR 1.79, CI 1.00-3.20). The risk of insomnia still increased after correction for socioeconomic variables (Model 2; OR 1.83, CI 1.01-3.31) but no significant differences were observed after correction for medical illnesses and lifestyle habits (Model 3; OR 1.50, CI 0.81-2.79). In the lowincome group, depression did not increase the risk of insomnia in any of the three models (Model 1: OR 1.40, CI 0.424.67; Model 2: OR 1.67, CI 0.47-5.90; Model 3: OR 2.16, CI 0.60-7.76), in the high-income group, however, the risk of insomnia was lower in current smoker (OR 0.37, CI 0.14-0.94). Although the risk of insomnia was not influenced by noise, an increased risk of insomnia was observed in participants with depression (Model 1: OR 17.11, CI 3.95-74.10; Model 2: OR 16.16, CI 3.60-72.89; Model 3: OR 16.29, CI 3.38-78.44) and in those who are divorced, separated, or bereaved compared to those who are married (Model 2: OR 4.45, CI 1.5013.21; Model 3: OR 5.12, CI 1.65-15.87). Auditory acuity and noise sensitivity were not significantly associated with an increased risk of insomnia, except for second model in the lowincome group (OR 1.12, CI 1.01-1.24) (Table 4).

\section{DISCUSSION}

The purpose of the present study was to determine the correlation between environmental noise and insomnia based on factors associated with the residential environment and socioeconomic status. We observed no significant relations in the prevalence of insomnia according to increases in the level of noise exposure. When divided according to income level, increases in insomnia were observed as noise levels increased in the low-income group, although no correlation was observed between the level of noise exposure and insomnia in the high-income group. In low-income group, after correct- ing for existing factors that may influence insomnia (e.g., anxiety, depression, noise sensitivity), the risk of insomnia increased 1.83-fold in individuals exposed to noise at $60 \mathrm{~dB}$ or higher, relative to that observed in individuals exposed to noise levels under $50 \mathrm{~dB}$. This result was similar after adjusting sociodemographic factors. However, after lifestyle-related factors and physical illnesses were corrected, the effects of noise on insomnia was not significant statistically (Table 4). Nonetheless, these results indicate that income levels influence the correlation between noise exposure and insomnia.

Although we observed no increase in the prevalence of insomnia according to increases in noise levels across all participants of the present study, we observed that the proportion of individuals experiencing insomnia increased along with increases in noise levels in the low-income group. There might be various explanation for this result. First, as we mentioned in the introduction, income level can have a significant impact on residential choice. In our study average noise level was lower in the low-income group, which means insomnia was not simply determined by the magnitude of the noise. Instead, low-income housing may be more likely to have features such as ineffective insulation and thinner wall, making them more vulnerable to environmental noise. In Seoul, although high-income populations are more exposed to road traffic noise, they prefer apartment which is usually soundproof by double- or triple-glazed window. On the other hand, low-income populations have less opportunity to protect themselves by equipping their dwelling with soundproof. Second, low income itself can be a risk of insomnia. Previous studies have consistently reported an inverse relationship between income and insomnia. ${ }^{50-53}$ A 6-year observational study involving 3,391 adults between the ages of 35 and 75 in Switzerland revealed that low socioeconomic status (based on income and occupation) was associated with lower sleep quality, longer sleep latency, and a 1.47-fold increase in the prevalence of insomnia, when compared with high socioeconomic status. ${ }^{51}$ Furthermore, a 20-year prospective study of nearly 1,000 adults in Scotland revealed that low socioeconomic status was associated with difficulty falling asleep, and an increased risk of insomnia over time. ${ }^{50}$

After dividing participants of the present study based on average monthly household income, we confirmed that different factors such as noise, depression, marital status might influence insomnia according to income level (Table 4). Previous research has demonstrated that genetic, neurophysiological, cognitive and behavioral factors precipitate and predispose individuals to insomnia, and that perpetuation of such factors results in chronic insomnia. ${ }^{54}$ Sleep structure is not only influenced by age and gender, ${ }^{55}$ but also by chronic stress associated with daily life, anxiety, and poor sleep hygiene. ${ }^{56}$ As such, 
it is difficult to determine the long-term effect of noise on insomnia in isolation. The fact that a variety of factors contribute to chronic insomnia suggests that insomnia represents a complex clinical disorder that interacts with and can be perpetuated by multiple factors. ${ }^{57}$ Thus, the present study is significant in its attempt to examine the association among objective noise indices, socioeconomic/health factors, and the risk of insomnia.

In the present study, we observed that depression predicted insomnia in the high-income group, although no such correlation was observed in the low-income group. No significant influence of anxiety on the risk of insomnia was observed in either income group. Insomnia is included among the diagnostic criteria for depression, while anxiety has also been regarded as a main cause of insomnia. ${ }^{58-60}$ Previous studies found that, although there is an increased risk of chronic insomnia in the low socioeconomic group, this risk is relatively low relative to the influence of underlying mental disorders on insomnia. ${ }^{50}$ Our study findings suggest that mental health status predicts the risk of insomnia only in high socioeconomic group. However, it is possible that because of the small sample size who are classified as depression group, the present study failed to reveal a significant difference due to the larger confidence interval. Therefore, further studies involving larger numbers of participants are required to verify our findings.

When the regression model was adjusted for lifestyle factors that can influence sleep hygiene and mental health disorders, no significant increases in the prevalence of insomnia were observed (Table 4). Although shift work status, alcohol consumption, smoking, caffeine intake, exercise level and other such lifestyle habits are closely associated with insomnia, ${ }^{61-65}$ no such associations were observed in the present study except for smoking in low-income group. Shift work is a major risk factor for insomnia, ${ }^{57}$ but it was not a significant factor in this study. Because ISI measure the sleep disturbance of recent 2 weeks, ${ }^{40}$ more detailed information such as information on shift work for the last 2 weeks immediately before the survey and total sleep time is needed. Unfortunately, information on shift work was not available in our studies, we could not accurately assess the impact of shift work on sleep. Smoking is generally known to be associated with poor sleep quality and insomnia, ${ }^{61,66}$ but we had opposite result in this study. This could be as a result of considering only current smoking status based on self-report. As recent study emphasis longitudinal effect of smoking, it is necessary to review in a well-designed study in future. In addition, marital status affected insomnia prevalence in high-income group. Some studies report that family relationships are more important than family types. ${ }^{67}$ Nevertheless, previous studies show divorce and widowhood can increase the risk of insomnia, ${ }^{68,69}$ which is similar to our result. According to the guidelines developed by the World Health Organization in 2009, outside noise at night $\left(\mathrm{L}_{\text {night }}\right)$ should be limited to $40 \mathrm{~dB}$ to reduce the influence of environmental noise on health. ${ }^{11}$ In 2008, the Korean Ministry of Environment inserted a section on noise map creation as part of the Noise and Vibration Regulation Act, which has been used to establish recent regulations regarding noise exposure. ${ }^{70,71}$ Proper management of noise involves the measurement of local noise to inform both research and policy; however, such efforts remain in the beginning stages in Korea. Although some Korean studies have examined the association between noise annoyance and noise map data, ${ }^{72}$ or between aircraft noise and sleep quality, ${ }^{7}$ no studies have examined the influence of noise maps on mental health in residential areas.

However, the inherent limitations of noise maps in determining noise exposure should also be noted. Because noise was measured externally, it is difficult to determine the actual influence of the noise indoors. ${ }^{4}$ Moreover, as no reports have discussed the influence of objective noise exposure in the workplace or personal sleep hygiene on insomnia, caution must be taken when interpreting our results. Previous studies have also reported that the maximum noise value $\left(\mathrm{L}_{\max }\right)$ exerts a direct negative impact of the quality of sleep, ${ }^{11}$ and that the frequency or source of the noise may also be associated with insomnia. ${ }^{25}$ Thus, the information provided by noise maps is limited in that it cannot be used to accurately determine an individual's response to noise exposure. Research has also indicated that noise influences health in various ways, depending on the type and characteristics of the noise, although such differences are difficult to measure due to the lack of objective assessment methods. ${ }^{6}$ The cross-sectional design of the present study did not allow for inferences regarding the causal relationship between noise exposure and sleep. In addition, when considering the influence of income level on sleep, it is difficult to determine the overall income characteristics of a given region based on average income alone. Because the income gap differs greatly among various regions, different results may be achieved by dividing income into multiple levels. ${ }^{51,52}$ Moreover, the relationship between mental health disorders and income may constitute a feedback loop, influencing academic achievement or the selection of a workplace, ${ }^{73,74}$ rendering it difficult to capture the true dynamics of this interaction.

The strengths of this study are as follows. First, we considered the comprehensive influence of environmental factors such as sociodemographic variables, lifestyle, and medical illness in relation to noise and insomnia. Second, this study is a large-scale epidemiological study involving more than 700 people. Third, the present study is the first to examine the as- 
sociation between environmental noise via objective noise maps and insomnia in a large sample. Fourth, we used mental health assessment tools such as CES-D and STAI, which are widely used in epidemiological studies. Previous studies have utilized subjective indices such as sensitivity or annoyance to determine the influence of noise on health. ${ }^{75-77}$ However, noise annoyance is inevitably influenced by an individual's noise sensitivity, personality and lifestyle habits. ${ }^{78}$

The results of the present study suggest that income level plays an important role in mediating the complex relationship between noise and sleep: Noise exerted a greater influence on insomnia in the low-income group than in the high-income group, while depression exerted a greater influence on insomnia in the high-income group. Thus, the clinical effects of noise exposure may differ based on income level, as those with higher income may choose to live in residential areas with low noise exposure, while differences in mental health may also act as protective factors. Such differences may also be associated with variations in population density, air pollution, educational facilities, ${ }^{31}$ and levels of anxiety and depression. ${ }^{50}$ Therefore, the degree of noise exposure and income distribution must be considered when establishing future policies due to the need for more practical and inclusive noise provisions.

The present study aimed to examine the potential role of income level in mediating the influence of noise exposure on mental health in an urban population. Our findings indicate that low income is associated with an increased risk of insomnia as noise levels increase, although no such correlation was observed for individuals of the high-income group. While it is difficult to conclude that noise is a direct cause of insomnia due to the influence of various other factors such as lifestyle habits, these findings suggest that individuals with low income are more vulnerable to the deleterious effects of environmental noise. However, caution should be taken when interpreting the findings of the present study, as the influence of traffic noise was based on outdoor measurements. As it is difficult to verify these findings using more precise values of indoor noise exposure, suitable provisions can be established for at-risk regions based on income level.

\section{Acknowledgments}

This study was supported by the Korea Ministry of Environment (MOE) as the Environmental Health Action Program (grant number: 2014001350001).

\section{REFERENCES}

1. Ellis JG, Perlis ML, Neale LF, Espie CA, Bastien CH. The natural history of insomnia: focus on prevalence and incidence of acute insomnia. J Psychiatr Res 2012;46:1278-1285.

2. Cho YW, Shin WC, Yun CH, Hong SB, Kim J, Earley CJ. Epidemiology of insomnia in korean adults: prevalence and associated factors. J Clin Neurol 2009;5:20-23.

3. Roth T. Insomnia: definition, prevalence, etiology, and consequences. J
Clin Sleep Med 2007;3(5 Suppl):S7-S10.

4. WHO Regional Office for Europe. Burden of Disease from Environmental Noise: Quantification of Healthy Years Life Lost in Europe. Copenhagen: World Health Organization; 2011.

5. Kim M, Chang SI, Seong JC, Holt JB, Park TH, Ko JH, et al. Road traffic noise: annoyance, sleep disturbance, and public health implications. Am J Prev Med 2012;43:353-360.

6. Pirrera S, De Valck E, Cluydts R. Nocturnal road traffic noise: a review on its assessment and consequences on sleep and health. Environ Int 2010;36:492-498.

7. Kim SJ, Chai SK, Lee KW, Park JB, Min KB, Kil HG, et al. Exposureresponse relationship between aircraft noise and sleep quality: a community-based cross-sectional study. Osong Public Health Res Perspect 2014;5:108-114.

8. Berglund B, Lindvall T, Schwela DH. Guidelines for Community Noise. Geneva: World Health Organization; 1999.

9. Lee J, Gu J, Park H, Yun H, Kim S, Lee W, et al. Estimation of populations exposed to road traffic noise in districts of Seoul metropolitan area of Korea. Int J Environ Res Public Health 2014;11:2729-2740.

10. Lee JH, Lee JM, Shim CS, Bhang SY, Jung KS. The Health Effects of the Noise (II). Inchon: National Institute of Environmental Research; 2012.

11. WHO Regional Office for Europe. Night Noise Guidelines for Europe. Copenhagen: World Health Organization Europe; 2009.

12. Munzel T, Gori T, Babisch W, Basner M. Cardiovascular effects of environmental noise exposure. Eur Heart J 2014;35:829-836.

13. Gilles A, De Ridder D, Van Hal G, Wouters K, Kleine Punte A, Van de Heyning P. Prevalence of leisure noise-induced tinnitus and the attitude toward noise in university students. Otol Neurotol 2012;33:899-906.

14. Wright BA, Peters ER, Ettinger U, Kuipers E, Kumari V. Moderators of noise-induced cognitive change in healthy adults. Noise Health 2016;18: 117-132.

15. Hume KI, Brink M, Basner M. Effects of environmental noise on sleep. Noise Health 2012;14:297-302.

16. Basner M, Brink M, Bristow A, de Kluizenaar Y, Finegold L, Hong J, et al. ICBEN review of research on the biological effects of noise 20112014. Noise Health 2015;17:57-82.

17. Basner M, Brink M, Elmenhorst EM. Critical appraisal of methods for the assessment of noise effects on sleep. Noise Health 2012;14:321-329.

18. Elliott R, McKinley S, Cistulli P, Fien M. Characterisation of sleep in intensive care using 24-hour polysomnography: an observational study. Crit Care 2013;17:R46.

19. Friese RS, Diaz-Arrastia R, McBride D, Frankel H, Gentilello LM. Quantity and quality of sleep in the surgical intensive care unit: are our patients sleeping? J Trauma 2007;63:1210-1214.

20. Pisani MA, Friese RS, Gehlbach BK, Schwab RJ, Weinhouse GL, Jones SF. Sleep in the intensive care unit. Am J Respir Crit Care Med 2015;191: 731-738.

21. Carter NL. Transportation noise, sleep, and possible after-effects. Environ Int 1996;22:105-116.

22. Skånberg A, Öhrström E. Sleep disturbances from road traffic noise: a comparison between laboratory and field settings. J Sound Vibrat 2006; 290:3-16.

23. van den Berg F, Verhagen C, Uitenbroek D. The relation between scores on noise annoyance and noise disturbed sleep in a public health survey. Int J Environ Res Public Health 2014;11:2314-2327.

24. Frei P, Mohler E, Roosli M. Effect of nocturnal road traffic noise exposure and annoyance on objective and subjective sleep quality. Int J Hyg Environ Health 2014;217:188-195.

25. Murphy E, King EA. Strategic environmental noise mapping: methodological issues concerning the implementation of the EU Environmental Noise Directive and their policy implications. Environ Int 2010;36:290298.

26. Lee SW, Chang SI, Park YM. Utilizing noise mapping for environmental impact assessment in a downtown redevelopment area of Seoul, Korea. Appl Acoust 2008;69:704-714. 
27. Stokols D. Establishing and maintaining healthy environments. Toward a social ecology of health promotion. Am Psychol 1992;47:6-22.

28. Szasz A, Meuser M. Environmental inequalities: literature review and proposals for new directions in research and theory. Curr Sociol 1997; 45:99-120.

29. Flacke J, Schule SA, Kockler H, Bolte G. Mapping environmental inequalities relevant for health for informing urban planning interventions- a case study in the city of Dortmund, Germany. Int J Environ Res Public Health 2016;13:711.

30. Hite D. A random utility model of environmental equity. Growth Change 2000;31:40-58.

31. Evans GW, Kantrowitz E. Socioeconomic status and health: the potential role of environmental risk exposure. Annu Rev Public Health 2002; 23:303-331.

32. Havard S, Reich BJ, Bean K, Chaix B. Social inequalities in residential exposure to road traffic noise: an environmental justice analysis based on the RECORD Cohort Study. Occup Environ Med 2011;68:366-374.

33. Kruize H, Bouwman AA. Environmental (in)equity in the Netherlands: a case study on the distribution of environmental quality in the Rijnmond region. RIVM Report 550012003/2004. Ministry of Public Housing. Available at http://www.rivm.nl/bibliotheek/rapporten/550012003. pdf

34. Lam KC, Chan PK. Socio-economic status and inequalities in exposure to transportation noise in Hong Kong. Open Environ Sci 2008;2:107113.

35. Dale LM, Goudreau S, Perron S, Ragettli MS, Hatzopoulou M, Smargiassi A. Socioeconomic status and environmental noise exposure in Montreal, Canada. BMC Public Health 2015;15:205.

36. Woo YJ, Kim SW. Using New IT in Area Sampling: An Experience in Korea. Proceedings of Joint Statistical Meeting; 2012 Jul 28-Aug 2; San Diego, CA. Alexandria, VA: American Statistical Association; 2012.

37. EU Directive. Directive 2002/49/EC of the European parliament and the Council of 25 June 2002 relating to the assessment and management of environmental noise. Off J Eur Comm 2002;12-25.

38. Babisch W, Dutilleux G, Paviotti M, Backman A, Gergely B, McManus B. Good Practice Guide on Noise Exposure and Potential Health Effects. Copenhagen: European Environment Agency; 2010.

39. ISO I. TS 15666 Technical Specification, Acoustics-Assessment of Noise Annoyance by Means of Social and Socio-Acoustic Surveys. Genenva: International Organization for Standardization; 2003.

40. Morin CM. Insomnia: Psychological Assessment and Management. New York: Guilford Press; 1993.

41. Cho YW. Sleepiness scale and sleep hygiene. J Korean Sleep Res Soc 2004;1:12-23.

42. Johns MW. A new method for measuring daytime sleepiness: the Epworth Sleepiness Scale. Sleep 1991;14:540-545.

43. Morin CM, Belleville G, Belanger L, Ivers H. The Insomnia Severity Index: psychometric indicators to detect insomnia cases and evaluate treatment response. Sleep 2011;34:601-608.

44. Radloff LS. The CES-D Scale: a self-report depression scale for research in the general population. Appl Psychol Meas 1977;1:385-401.

45. Cho MJ, Kim KH. Diagnostic validity of the CES-D (Korean version) in the assessment of DSM-III-R major depression. J Korean Neuropsychiatr Assoc 1993;32:381-399.

46. Weissman MM, Sholomskas D, Pottenger M, Prusoff BA, Locke BZ. Assessing depressive symptoms in five psychiatric populations: a validation study. Am J Epidemiol 1977;106:203-214.

47. Spielberger CD, Gorsuch RL, Lushene RE. Manual for the State-Trait Anxiety Inventory. Palo Alto: Consulting Psychologists Press; 1983.

48. Kim JT, Shin DK. A study based on the standardization of the STAI for Korea. New Med J 1978;21:69-75.

49. Kim JT. The Relationship between Trait Anxiety and Sociality. Seoul: Korea University Graduate School; 1978.

50. Green MJ, Espie CA, Benzeval M. Social class and gender patterning of insomnia symptoms and psychiatric distress: a 20 -year prospective cohort study. BMC Psychiatry 2014;14:152.

51. Stringhini S, Haba-Rubio J, Marques-Vidal P, Waeber G, Preisig M, Guessous I, et al. Association of socioeconomic status with sleep disturbances in the Swiss population-based CoLaus study. Sleep Med 2015;16:469476.

52. Lallukka T, Sares-Jaske L, Kronholm E, Saaksjarvi K, Lundqvist A, Partonen $\mathrm{T}$, et al. Sociodemographic and socioeconomic differences in sleep duration and insomnia-related symptoms in Finnish adults. BMC Public Health 2012;12:565.

53. Freeman A, Tyrovolas S, Koyanagi A, Chatterji S, Leonardi M, AyusoMateos JL, et al. The role of socio-economic status in depression: results from the COURAGE (aging survey in Europe). BMC Public Health 2016;16:1098.

54. Riemann D, Spiegelhalder K, Espie C, Pollmacher T, Leger D, Bassetti C, et al. Chronic insomnia: clinical and research challenges--an agenda. Pharmacopsychiatry 2011;44:1-14.

55. Thase ME. Depression and sleep: pathophysiology and treatment. Dialogues Clin Neurosci 2006;8:217-226.

56. Ahn DH. Insomnia: causes and diagnosis. Hanyang Med Rev 2013;33: 203-209.

57. Khoury J, Doghramji K. Primary sleep disorders. Psychiatr Clin North Am 2015;38:683-704.

58. Jansson-Frojmark M, Lindblom K. A bidirectional relationship between anxiety and depression, and insomnia? A prospective study in the general population. J Psychosom Res 2008;64:443-449.

59. Sivertsen B, Salo P, Mykletun A, Hysing M, Pallesen S, Krokstad S, et al. The bidirectional association between depression and insomnia: the HUNT study. Psychosom Med 2012;74:758-765.

60. Taylor DJ, Lichstein KL, Durrence HH, Reidel BW, Bush AJ. Epidemiology of insomnia, depression, and anxiety. Sleep 2005;28:1457-1464.

61. Cohrs S, Rodenbeck A, Riemann D, Szagun B, Jaehne A, Brinkmeyer J, et al. Impaired sleep quality and sleep duration in smokers-results from the German Multicenter Study on Nicotine Dependence. Addict Biol 2014;19:486-496.

62. Feige B, Gann H, Brueck R, Hornyak M, Litsch S, Hohagen F, et al. Effects of alcohol on polysomnographically recorded sleep in healthy subjects. Alcohol Clin Exp Res 2006;30:1527-1537.

63. Drake C, Roehrs T, Shambroom J, Roth T. Caffeine effects on sleep taken 0, 3, or 6 hours before going to bed. J Clin Sleep Med 2013;9:1195-1200.

64. Kline CE. The bidirectional relationship between exercise and sleep: implications for exercise adherence and sleep improvement. Am J Lifestyle Med 2014;8:375-379.

65. Taylor DJ, Mallory LJ, Lichstein KL, Durrence HH, Riedel BW, Bush AJ. Comorbidity of chronic insomnia with medical problems. Sleep 2007:30:213-218.

66. Wetter DW, Young TB. The relation between cigarette smoking and sleep disturbance. Prev Med 1994;23:328-334.

67. Chen JH, Waite LJ, Lauderdale DS. Marriage, relationship quality, and sleep among US older adults. J Health Soc Behav 2015;56:356-377.

68. Smagula SF, Stone KL, Fabio A, Cauley JA. Risk factors for sleep disturbances in older adults: evidence from prospective studies. Sleep Med Rev 2016;25:21-30.

69. Garbarino S, Lanteri P, Durando P, Magnavita N, Sannita WG. Co-morbidity, mortality, quality of life and the healthcare/welfare/social costs of disordered sleep: a rapid review. Int J Environ Res Public Health 2016; 13. pii:E831.

70. Jeong JH, Yuk DG, Song BG, Kim HC. A study on the change of road traffic noise at the roadside apartments according to the traffic management. J Korean Soc Transp 2009;27:29-38.

71. Sun H. Establishment on management plan of environmental noise with noise map. J Environ Impact Assess 2011;20:123-131.

72. Lim C, Kim J, Hong JY, Lee S. The relationship between railway noise and community annoyance in Korea. J Acoust Soc Am 2006;120:20372042.

73. Hudson CG. Social class and mental illness correlation: implications of 
the research for policy and practice. J Soc Soc Welfare 1988;15:27-54.

74. Hudson CG. Socioeconomic status and mental illness: tests of the social causation and selection hypotheses. Am J Orthopsychiatry 2005; 75:3-18.

75. Orban E, McDonald K, Sutcliffe R, Hoffmann B, Fuks KB, Dragano N, et al. Residential road traffic noise and high depressive symptoms after five years of follow-up: results from the Heinz Nixdorf recall study. Environ Health Perspect 2016;124:578-585.
76. Huang J, Guo B, Guo XB. Research progress in health impact of traffic noise. Beijing Da Xue Xue Bao 2015;47:555-558.

77. Nivison ME, Endresen IM. An analysis of relationships among environmental noise, annoyance and sensitivity to noise, and the consequences for health and sleep. J Behav Med 1993;16:257-276.

78. van Kamp I, Davies H. Noise and health in vulnerable groups: a review. Noise Health 2013;15:153-159. 